\title{
Measuring Hotel Risk and Financing
}

\author{
Peng Liu and Daniel Quan
}

The last couple of chapters have discussed your potential for success as the owner of a hospitality business and related real estate. It's true that the possibilities are great, but before you plunge ahead, you should realize that you are considering one of the riskiest forms of commercial real estate investment. Owning a hotel is unlike owning any other form of real estate. As a hotel owner, you face not only the usual risks associated with commercial real estate investments but also hotel-specific risks. Depending on your level of optimism, this can either represent a golden opportunity to obtain a higher rate of investment return or be a signal to consider other property types with lower risks. In either case, your correct decision as to whether to own a hotel will depend on your ability to not only understand the nature of hotel risks, but also to develop strategies to mitigate their effects.

First, let's look at the factors that differentiate a hotel from other real estate investments. A primary difference is the absence of long-term tenant leases, a feature common to most other forms of commercial real estate ownership. Instead of tenants that commit to multiyear lease contracts, your hotel will have "tenants" (hotel guests) who usually stay for just a matter of days. Whereas the lease for a long-term tenant will probably have rent indexation or escalation that provides for increased payments, your new hotel "tenants" will pay prevailing market "rents" or daily rates, which might be higher or lower than what you have projected. These new market rates are influenced by factors that are out of your control, including the condition of the overall economy and the rates charged by your competitors. While hotels can indeed be a highly profitable investment vehicle, it's critical that you understand exactly the nature of the risks you are undertaking.

To turn a profit, hotel property investors or managers must understand and manage hotels' "daily lease" feature. In this chapter, we investigate this source of uncertainty and develop a framework to characterize this effect. Furthermore, we explore methods that you can use to mitigate such risks.

Our approach is based on our consideration of the hotel as a financial asset that generates a cash flow stream, as described in previous chapters. In this context, the lack of tenant commitment corresponds to uncertainty in the cash flow during the time you hold the property. We apply welldeveloped portfolio allocation tools drawn from the analysis of fixed-income securities to show you how 
to analyze this problem. In addition, we develop standard portfolio risk measurement tools within the context of hotels when they are viewed as investment vehicles.

\section{Hotel Risk}

As we said, the daily lease feature distinguishes hotels from other real estate investments. To review, you would expect two primary revenue sources to generate financial returns for your real estate investment, namely, changes in the value of the asset and an income stream (after tax cash flow) while you hold the property. Property values in a given neighborhood generally change more or less in concert. For example, if commercial values in Midtown Manhattan appreciate, this increase would likely be felt by all commercial properties. So, that's the appreciation part of the equation.

Hotels still have to account for their variable income streams. The lack of tenant commitment introduces substantial risk for hotel investors, given the variable demand for hotel rooms. We all saw the cancellations of corporate room bookings during the Great Recession. As we write this in the early stages of an economic upswing, bookings are gradually increasing and rates have recovered somewhat. Taken together, changes in rate and occupancy cause hotel income-and your cash flow-to be quite volatile over the course of a business cycle. Therein lies the risk for investors. This problem is further complicated by the nature of hotel cash flows and their dependence on the cost of wages and supplies, as well as the costs of financing. Hotels' volatility, which is a common measure of risk, gives rise to the perception of hotels as a risky type of investment property.

Although an increase in risk does not generally deter investments, it does increase the cost of an investment. Hotel mortgage lenders, for example, routinely price this risk when they underwrite hotel mortgages. A property with a volatile cash flow stream may see periods when there is insufficient cash to make the scheduled mortgage payments, which constitutes a default that would lead to foreclosure. Since default and foreclosure are extremely costly to lenders (and they really don't want to own your hotel), this risk is priced by charging a higher rate, usually referred to as a risk premium.

The chart in Figure 22.1 shows the extent of that risk premium, as defined by lenders. The graph shows the spread at the time of loan origination (SATO) for mortgage loans for several property types originated for the securitized commercial mortgage-backed securities market. These spreads, defined as increments to the Treasury bond rate, are essentially the risk premiums charged for different types of real estate loans.

As you can see, among the 10 property types, hotels have the highest spreads over this periodthe highest risk premiums. The hotel loan spread peaked after September 11, 2001, at 320 basis points 
or a 3.2 percent spread over Treasury, and it took about three years for the shock to wear off. Investors were concerned that the events of that day might result in people curtailing their travel, which would, of course, decrease the lodging sector's cash flow and increase the likelihood of default. This didn't really occur, but even for the period before September 11, 2001, it is clear that hotels had the highest spreads among all property types, again demonstrating the view of hotels as a risky investment.

The immediate consequence of this perception is a higher borrowing cost and the application of conservative underwriting criteria for hotel loans. This increased perception of risks suggests that the required rates of return for hotel investments should also exceed those of other property types since investors will seek additional returns to compensate for these increased costs.

Figure 22.1

\section{Loan Risk Spread}

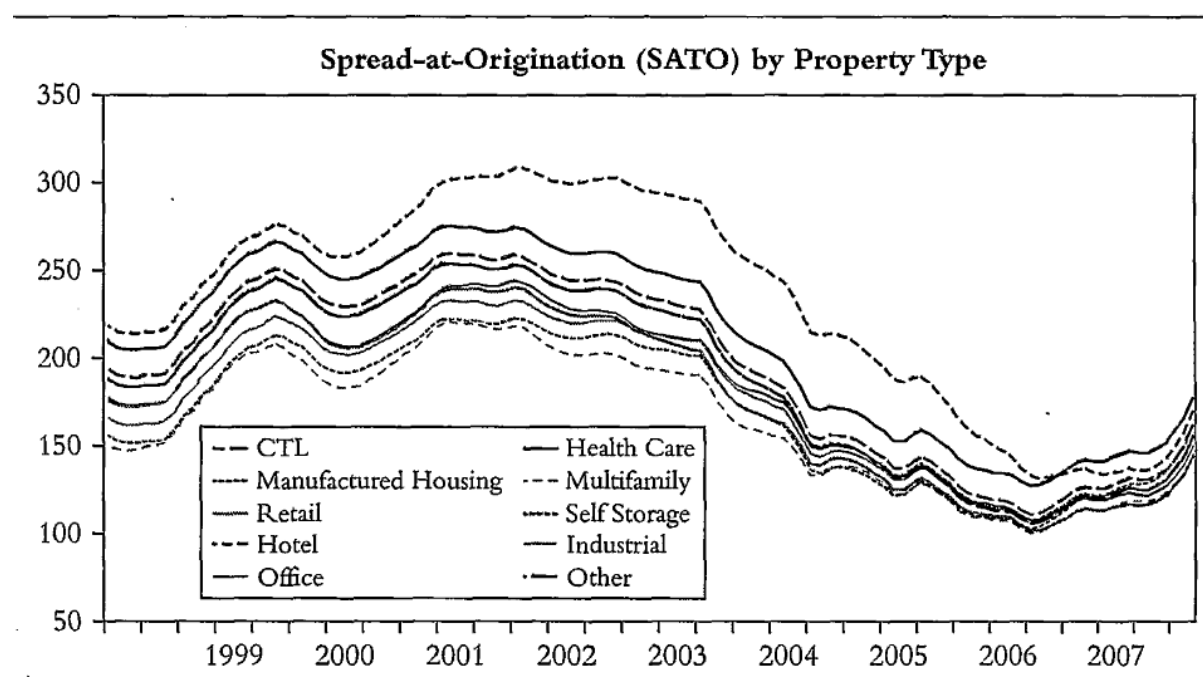

Note: This chart shows the historical trend of the average loan spread (in basis point) over Treasury at origination for each property type. The SATOs are estimated based on loan rates of fixed rate CMBS loans, normalized for loan size and LTV to capture the true difference in SATO by property type.

Data source: Lehman Brothers

\section{Measuring Hotel Risk}

Chapter 18 discussed the hotel valuation tool known as the discounted cash flow model. This approach reflects the fact that hotel investors value the stream of future cash flows that ownership affords. A valuation formula is used to determine a property's market value using the hotel's cash flow or its net operating income (NOI). Alternatively, if after-tax cash flow figures are used, this valuation formula determines the investment value or the investors' private valuation of the hotel. The 
investment analysis typically entails a comparison between these two values, with investments deemed favorable if their value exceeds the property's market value.

Both applications use the discount rate in the model. It is common practice to select a discount rate that reflects the opportunity cost of capital for the investor at the time the decision is made. There is no guarantee, however, that the discount rate-not the investor's opportunity cost-will remain constant throughout the hotel's investment life. In fact, the discount rate will surely change over time, along with the investors' valuation, even if the property cash flows have not changed. As you will see from the following expression, because the discount rate is in the denominator, an increase in this rate will decrease the value of the hotel, and likewise a decrease in the rate increases hotel valuation. It is therefore important to understand and quantify the sensitivity of our hotel valuation to such changes. A powerful tool to measure this sensitivity is called duration.

$V=\frac{N O I_{1}}{\left(1+r_{1}\right)}+\frac{N O I_{2}}{\left(1+r_{2}\right)^{2}}+\cdots+\frac{N O I_{T}}{\left(1+r_{T}\right)^{T}}+\frac{P_{T}}{\left(1+r_{T}\right)^{T}}$

In this equation, $r_{i}$ represents periodic discount rates; $\mathrm{NOI}_{i}(i=1,2, \ldots \mathrm{T})$ are net operating income streams; and $P_{T}$ is the projected equity reversion value at time $\mathrm{T}$, which can be estimated using the next period $\mathrm{NOI}\left(\mathrm{NOI}_{T+1}\right)$ divided by terminal capitalization rate $\left(\mathrm{Cap}_{T}\right)$.

$P_{T}=\frac{N O I_{T+1}}{\operatorname{Cap}_{T}}$

\section{Duration-An Introduction}

Duration is common tool used in the analysis of fixed-income securities, such as bonds. ${ }^{1}$ Much like our real estate application in this chapter, a bond's price is the present value of its coupon payments (our property's NOI) and its redemption value at maturity (property reversion value at the end of the holding period). A bond's price, therefore, is influenced by changes in the interest rate or bond yield, and duration determines the percentage change in the bond's price for a given percentage change in yield. A similar thing happens for hotel properties. In our application, we are interested in the change in property value for a given change in the discount rate.

Before developing this tool in the context of our hotel property application, it is important to know under what circumstances the discount rate can change. The discount rate comprises numerous market factors, most notably the expectations regarding currency inflation or deflation, explained next. 
To understand why the discount rate may change, you should consider the underlying factors that influence its movement (see Figure 22.2). The first basic component is the risk-free interest rate. This is largely a conceptual notion since no investments are risk free. Nevertheless, we have a proxy for this rate, the U.S. Treasury bill rate, since this instrument is widely viewed as one of the safest investments in the world.

Figure 22.2

Factors Driving the Hotel Investment Discount Rate

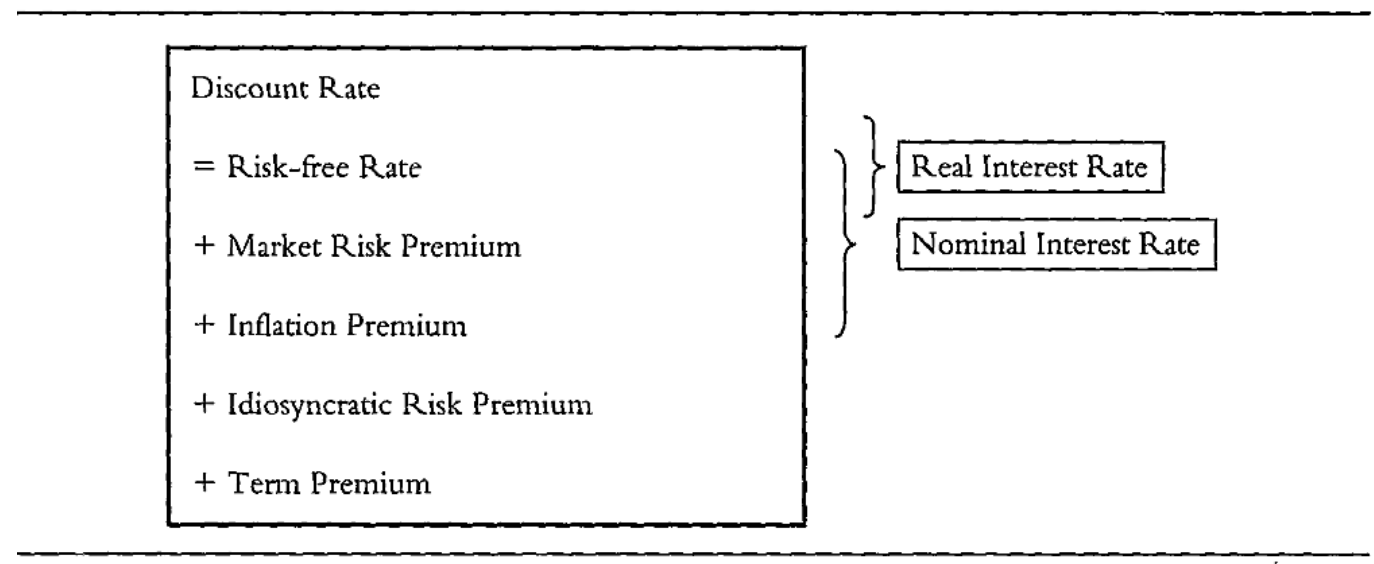

The second component is a market risk premium, meant to reflect the risk of the overall economy, such as when the economy slowed down severely in 2007-2009 after the financial markets collapsed. In such a difficult economic climate, borrowers holding loans that originated during more favorable economic times may experience financial hardship leading to loan delinquency. For lenders to extend a new loan in difficult times, it is reasonable for them to require additional (or higher) payments to compensate for this increased risk. You saw this increased risk premium in Figure 22.1. It is expressed as an increment to the discount rate. An equivalent interpretation of why the discount rate should increase in an uncertain economy is that a given cash flow has less value in the future than it does today because, in an uncertain economy, it is more likely that a borrower will be unable to make a future payment. This makes the value of future payments lower, in light of this increased uncertainty.

The third component is the inflation premium, which is expressed as the inflation rate. If the inflation rate is expected to be 3 percent over the investment period, the inflation premium is likewise 3 percent, which, when added to the risk-free rate, will yield the nominal interest rate.

The nominal interest rate can be understood as the interest rate one observes on the market, such as the widely published prime rate or LIBOR (the London Interbank Offered Rate). Like the prime 
rate, the nominal interest rate reflects the cost of borrowing for a given loan. Another indicator of the nominal interest rate is the rate paid by the U.S. government on Treasury securities. The purchase of socalled T-bills can be viewed as a buyer extending a loan to the government-in effect lending the government the price of the bond in exchange for receiving a periodic payment by the government in the form of coupon payments.

The rate at which the government borrows varies depending on the loan's term. When we plot these rates for various loan terms, the resulting plot is called the term structure of interest rates. The graph in Figure 22.3 shows an example of this term structure on July 27,2010 . Note that as the loan's term gets longer, the rate is generally higher. The simplest explanation for this effect is the increased risk associated with a promise to make loan payments over a longer horizon. A promised long-term loan repayment is generally riskier than a shorter-term loan repayment since more things can go wrong during the course of a lengthy loan. To reflect this increased risk, then, the lending rate should increase to compensate the lender. The difference in this increment between loans made in the short term and loans in the long term is called the term premium.

Figure 22.3

U.S. Treasury Rates

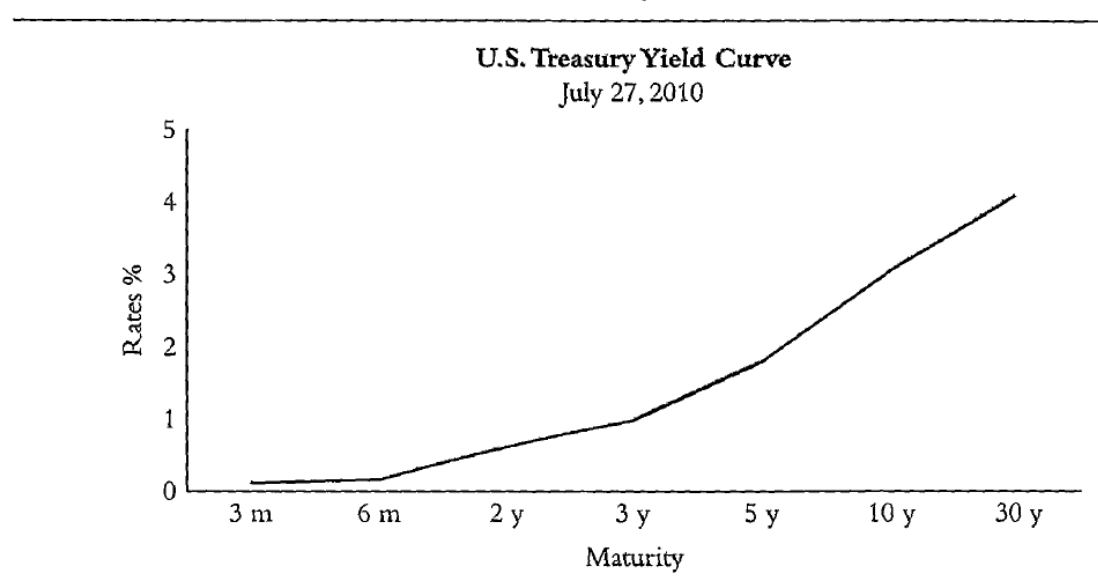

Data source: Federal Reserve.

You have perhaps noticed that long-term loans, those with maturities greater than five years, often have higher rates than those made for the short term. Equivalently, the discount rates used for longer-term payments should be higher than those for shorter-term payments. Let's point out the inconsistency in the usual hotel valuation formula's use of a single discount rate for all future cash flows. The proper discount rate should be different for each cash flow. Indeed, most other financial applications of the present value model use multiple discount rates, but the real estate industry still adopts the simplifying assumption of a constant discount rate. This also implies that this single discount 
rate should be some representative "average" value. For hotel investments, you will notice that most investors use a 10- to 20-year planning horizon; thus, the inclusion of a term premium is appropriate.

The fourth and final component of the risk premium is the idiosyncratic risk premium, which is specific to the particular investment. For example, a hotel located in an area where there is a higher risk of not achieving a desired level of revenue will have a higher risk premium than a hotel located in a more desirable area with a stronger cash flow stream.

\section{Duration-A Framework}

Because the discount rate includes numerous economic factors, a change in any individual component can lead to a corresponding change in the discount rate. This matter is further complicated by the fact that many of these terms are interrelated. If the U.S. Federal Reserve is working to decrease inflation by reducing the money supply, your inflation premium should decline. At the same time, however, the Fed's action can increase the short-term interest rate, thereby decreasing the term premium. You can see, therefore, that a measure that determines how changes in the overall discount rate may influence the value of a hotel investment can become an important tool not only to investigate the influence of changes in the individual components of the discount rate, but also to indicate how sensitive the value of a hotel is to changes in these components.

Let's look at the mathematics for real estate valuation based on discounted values of all predicted future cash flows. The present value of a hotel corresponds to the sum of its future income adjusted by the time of occurrence and the risk premium discounted for such investment.

Replacing periodic discount rates with an average discount rate, the value (V) of a hotel property is simplified by the following expression:

$V=\frac{N O I_{1}}{(1+R)}+\frac{N O I_{2}}{(1+R)^{2}}+\cdots+\frac{N O I_{T}+P_{T}}{(1+R)^{T}}$

As a hotel investor, it is sometimes possible for you to influence a property's cash flow by changing management companies or enacting cost-cutting measures. But you have no control over the discount rate even though changes in the discount rate have substantial influence over your property's valuation. An increase in the discount rate would decrease today's valuation of an otherwise same future NOI, resulting in a decrease in the overall hotel's valuation. Conversely, a decrease in the discount rate would increase the value of the hotel. Because of the importance (and uncertainty) of discount rate movements for hotel valuation, it's important for you to have a measure of the sensitivity of the value of 
your hotel to changes in the discount rate for a given set of NOls. This measure, commonly used in the same way for fixed-income securities, is called duration.

More formally, duration, $d$, is defined as

$$
d=-\frac{\partial V}{\partial(1+r)} \times \frac{(1+r)}{V}
$$

The first term to the right of the equals sign $(\partial \mathrm{V})$ is the partial derivative of $V$ with respect to a change in the discount rate, $r$. This term tells us how $V$ changes for a unit change in the $r$. However, because this measure alone does not account for scale, it is often more convenient to express this measure in percentage terms. The last term in the preceding expression normalizes the duration expression in terms of percentage changes. The following can thus be used as another notation for duration:

$\operatorname{Duration}(d)=-\frac{\% \text { change in } V}{\% \text { change in }(1+r)}=-\frac{\Delta V / V}{\Delta(1+r) /(1+r)}=-\frac{\Delta V}{\Delta(1+r)} \frac{(1+r)}{V}$

By applying the first expression to our hotel valuation formula, we see that duration can be calculated as in the following expression:

$$
\frac{\partial V}{\partial(1+r)}=\frac{-\mathrm{NOI}_{1}}{(1+r)^{2}}+\frac{-2 \mathrm{NOI}_{2}}{(1+r)^{3}}+\cdots+\frac{-T\left(N O I_{T}+P_{T}\right)}{(1+r)^{T+1}}
$$

Multiplying the right-hand side by - , and simplifying, we get

$$
d=-\frac{\partial V}{\partial(1+r)} \frac{(1+r)}{V}=\frac{1}{V} \frac{N_{1} I_{1}}{(1+r)^{1}}+\frac{2}{V} \frac{N_{2} I_{2}}{(1+r)^{2}}+\ldots+\frac{T}{V} \frac{\left(N_{T}+P_{T}\right)}{(1+r)^{T}}
$$

which is the final expression for duration.

Hotel Duration-A Working Example Let's look at how this equation functions. We work from the figures in the representative hotel operating pro forma shown in Figure 22.4. Using the NOI numbers from the bottom row of the table, you should be able to determine the duration of the hotel's cash flow stream. Before plugging in the duration expression, you need to calculate two numbers. First calculate the equity reversion value at the terminal year 5 , and then the discount rate. Using 6th-year cash flow with a terminal cap rate of 7.5 percent, we can figure the reversion value as follows: $\$ 24,856 / 7.5 \%=$ $\$ 331,413$ (assuming zero closing costs).

You can determine the average discount rate for your hotel if you know its current value. Let's say that the current value of the hotel is $\$ 265,000$. The average discount rate for the five-year holding period can be calculated from the following equation: 


$$
265,000=\frac{16,598}{(1+r)^{1}}+\frac{20,357}{(1+r)^{2}}+\frac{22,634}{(1+r)^{3}}+\frac{23,313}{(1+r)^{4}}+\frac{24,013+331,413}{(1+r)^{5}}
$$

Thus, the average discount rate (internal rate of return) is $11.871 \%$, and using duration formula, we see that duration is 4.41 years.

$$
\begin{aligned}
& d=\frac{1}{265,000}\left[\frac{16,598}{(1+.11871)^{1}}+\frac{2 \times 20,357}{(1+.11871)^{2}}+\frac{3 \times 22,634}{(1+.11871)^{3}}\right. \\
& \left.+\frac{4 \times 23,313}{(1+.11871)^{4}}+\frac{5 \times(24,013+331,413)}{(1+.11871)^{5}}\right]=4.41
\end{aligned}
$$

The duration of 4.41 seems like a small number, but it represents significant price elasticity compared to the discount rate. Going back to the inverse relationship of the discount rate and your property's value, we see that a 1 percent increase in the discount rate will reduce the valuation of your property by 4.41 percent, translating to an $\$ 11,691$ decline in asset value.

\section{Hotel Duration-Further Exploration}

We still have to account for the special case of hotels' "daily leases." Though the above analysis is correct for most fixed-income instruments with a fixed coupon payment, it is not entirely appropriate in our hotel application. Although often viewed as a negative feature of hotels, in fact the ability to roll over leases on a daily basis allows hotel operators to alter the room rate structure frequently. Thus, hotels have more flexibility than office building owners, who can only renegotiate a new lease on the expiration of an existing lease.

The benefit of frequently changing lease terms is that hotel operators can systematically alter room rates to reflect changing market conditions. These same conditions also may be factors that influence the discount rate. For example, during an inflationary period, room rates can increase to compensate for the lower purchasing power of a hotel's revenue stream. Furthermore, for changes in the nominal interest rate, hotel operators can alter the room rates to reflect changes in their opportunity cost of funds. You can see that when the discount rate changes, you'll probably want to change room rates to compensate for the negative effect.

Consider, for example, changes in the inflation rate. It is reasonable to assume that as operating costs increase due to inflation, hotels will respond by increasing their corresponding room rates (if market forces permit). In our hotel valuation equation, both the numerator and denominator are functions of inflation: 


$$
V=\sum_{t=1}^{T} \frac{\operatorname{NOI}_{t}(\text { inflation })}{(1+r(\text { inflation }))^{t}}
$$

As inflation increases, both the denominator (discount rate) and the numerator (NOI) increase, and the change in one partially offsets the change in the other. Other commercial real estate can't change its NO Is to account for inflation; thus, the effect of an increase in inflation will be much stronger for commercial buildings than for a hotel.

In this situation, the brief duration of a hotel can be an advantage, and the duration of hotel assets has interesting investment implications. In the context of achieving a diversified real estate portfolio investment, hotel ownership can make a strong contribution to portfolio diversity. Another implication is that due to the short duration of hotels, this investment vehicle is desirable if investors are concerned about changes in interest or discount rates.

Figure 22.4

Sample Five-Year Hotel Pro Forma

Representative Hotel 5-Year Pro Forma

\begin{tabular}{|c|c|c|c|c|c|c|c|c|c|c|c|c|}
\hline & \multicolumn{2}{|c|}{2009} & \multicolumn{2}{|c|}{2010} & \multicolumn{2}{|c|}{2011} & \multicolumn{2}{|c|}{2012} & \multicolumn{2}{|c|}{2013} & \multicolumn{2}{|c|}{2014} \\
\hline Available hotel rooms & \multicolumn{2}{|c|}{329} & \multicolumn{2}{|c|}{329} & \multicolumn{2}{|c|}{329} & \multicolumn{2}{|c|}{329} & \multicolumn{2}{|c|}{329} & \multicolumn{2}{|c|}{329} \\
\hline Available room nights & \multicolumn{2}{|c|}{120,085} & \multicolumn{2}{|c|}{120,414} & \multicolumn{2}{|c|}{120,085} & \multicolumn{2}{|c|}{120,085} & \multicolumn{2}{|c|}{120,085} & \multicolumn{2}{|c|}{120,414} \\
\hline Occupied room nights & \multicolumn{2}{|c|}{85,260} & \multicolumn{2}{|c|}{87,902} & \multicolumn{2}{|c|}{90,064} & \multicolumn{2}{|c|}{90,064} & \multicolumn{2}{|c|}{90,064} & \multicolumn{2}{|c|}{90,311} \\
\hline Occupancy & \multicolumn{2}{|c|}{$71.0 \%$} & \multicolumn{2}{|c|}{$73.0 \%$} & \multicolumn{2}{|c|}{$75.0 \%$} & \multicolumn{2}{|c|}{$75.0 \%$} & \multicolumn{2}{|c|}{$75.0 \%$} & \multicolumn{2}{|c|}{$75.0 \%$} \\
\hline Average daily rate & \multirow{2}{*}{\multicolumn{2}{|c|}{$\begin{array}{l}\$ 386.86 \\
\$ 274.67\end{array}$}} & $\$ 41$ & 94 & $\$ 43$ & 64 & $\$ 44$ & .68 & $\$ 46$ & .11 & $\$ 47$ & \\
\hline RevPAR & & & $\$ 30$ & & $\$ 32$ & .98 & $\$ 33$ & .76 & $\$ 34$ & 83 & $\$ 35$ & \\
\hline Days open & & & & & & & 36 & & 36 & & 36 & \\
\hline & Amount & Ratio & Amount & Ratio & Amount & Ratio & Amount & Ratio & Amount & Ratio & Arnount & Ratio \\
\hline REVENUES & & & & & & & & & & & & \\
\hline Rooms & $\$ 32,984$ & $39.9 \%$ & $\$ 36,386$ & $40.9 \%$ & $\$ 39,145$ & $41.3 \%$ & $\$ 40,320$ & $41.3 \%$ & $\$ 41,529$ & $41.3 \%$ & $\$ 42,892$ & $41.3 \%$ \\
\hline Food \& Beverage & $\$ 30,507$ & $36.9 \%$ & $\$ 32,396$ & $36.4 \%$ & $\$ 34,188$ & $36.1 \%$ & $\$ 35,214$ & $36.1 \%$ & $\$ 36,270$ & $36.1 \%$ & $\$ 37,460$ & $36.1 \%$ \\
\hline Telecommunications & $\$ 275$ & $0.3 \%$ & $\$ 293$ & $0.3 \%$ & $\$ 309$ & $0.3 \%$ & $\$ 318$ & $0.3 \%$ & $\$ 328$ & $0.3 \%$ & $\$ 338$ & $0.3 \%$ \\
\hline Golf & $\$ 8,603$ & $10.4 \%$ & $\$ 9,135$ & $10.3 \%$ & $\$ 9,641$ & $10.2 \%$ & $\$ 9,930$ & $10.2 \%$ & $\$ 10,228$ & $10.2 \%$ & $\$ 10,564$ & $10.2 \%$ \\
\hline Spa & $\$ 3,885$ & $4.7 \%$ & $\$ 4,125$ & $4.6 \%$ & $\$ 4,354$ & $4.6 \%$ & $\$ 4,484$ & $4.6 \%$ & $\$ 4,619$ & $4.6 \%$ & $\$ 4,770$ & $4.6 \%$ \\
\hline Other Departments & $\$ 6,321$ & $7.7 \%$ & $\$ 6,712$ & $7.5 \%$ & $\$ 7,084$ & $7.5 \%$ & $\$ 7,296$ & $7.5 \%$ & $\$ 7,515 \%$ & $7.5 \%$ & $\$ 7,762$ & $7.5 \%$ \\
\hline Total Revenues & $\$ 82,575$ & $100.0 \%$ & $\$ 89,048$ & $100.0 \%$ & $\$ 94,720$ & $100.0 \%$ & $\$ 97,562$ & $100.0 \%$ & $\$ 100,488$ & $100.0 \%$ & $\$ 103,787$ & $100.0 \%$ \\
\hline $\begin{array}{l}\text { DEPARTMENTAL } \\
\text { EXPENSES }\end{array}$ & & & & & & & & & & & & \\
\hline Rooms Expense & $\$ 8,906$ & $27.0 \%$ & $\$ 9,460$ & $26.0 \%$ & $\$ 9,982$ & $25.5 \%$ & $\$ 10,282$ & $25.5 \%$ & $\$ 10,590$ & $25.5 \%$ & $\$ 10,938$ & $25.5 \%$ \\
\hline Food \& Beverage Expense & $\$ 23,490$ & $77.0 \%$ & $\$ 24,297$ & $75.0 \%$ & $\$ 25,641$ & $75.0 \%$ & $\$ 26,410$ & $75.0 \%$ & $\$ 27,202$ & $75.0 \%$ & $\$ 28,095$ & $75.0 \%$ \\
\hline Telecommunications Expense & $\$ 413$ & $150.0 \%$ & $\$ 439$ & $150.0 \%$ & $\$ 463$ & $150.0 \%$ & $\$ 477$ & $150.0 \%$ & $\$ 491$ & $150.0 \%$ & $\$ 507$ & $150.0 \%$ \\
\hline Golf Expense & $\$ 4,473$ & $52.0 \%$ & $\$ 4,568$ & $50.0 \%$ & $\$ 4,820$ & $50.0 \%$ & $\$ 4,965$ & $50.0 \%$ & $\$ 5,114$ & $50.0 \%$ & $\$ 5,282$ & $50.0 \%$ \\
\hline Spa Expense & $\$ 2,409$ & $62.0 \%$ & $\$ 2,475$ & $60.0 \%$ & $\$ 2,612$ & $60.0 \%$ & $\$ 2,691$ & $60.0 \%$ & $\$ 2,771$ & $60.0 \%$ & $\$ 2,862$ & $60.0 \%$ \\
\hline
\end{tabular}


Figure 22.4 (Continued)

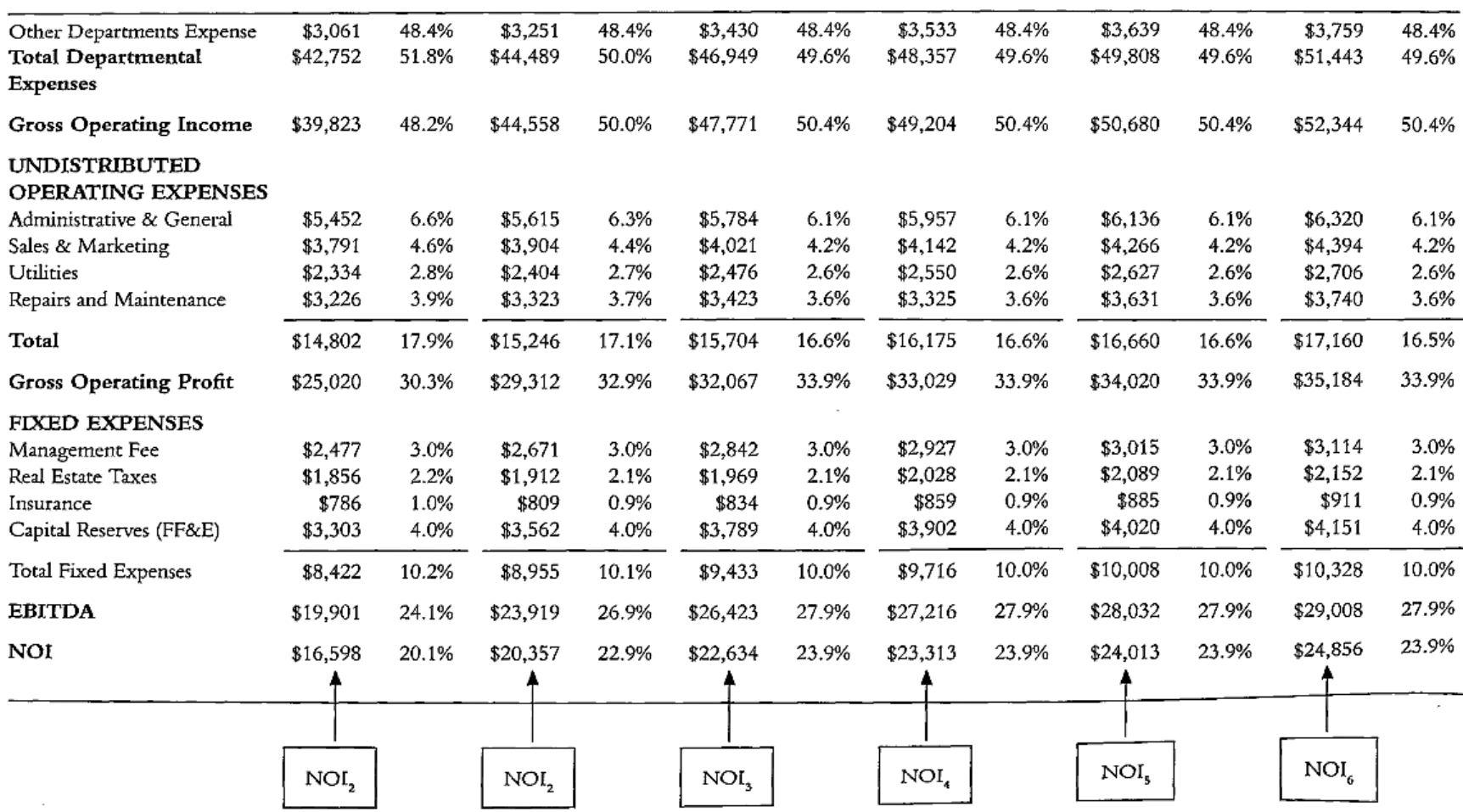

\section{Hotel Financing - Loan Choice}

With that background on the risk involved in hotel investments, let's look at the implications for loans. Most hotel investors finance their hotel acquisitions with mortgage contracts, but you'll face seemingly countless variations on the standard loan terms. Logically, you should seek out the loan with the lowest borrowing costs, but it's also critical that your payments are manage able in both good and bad times.

Because mortgage payments come from often volatile cash flows, a fixed-rate fixed-payment mortgage may not be the most desirable mortgage instrument. Figure 22.5 illustrates how, due to its high volatility, hotel income is more likely to fall under a debt service threshold that is constant over time.

As this example illustrates, a more appropriate mortgage may be one that allows for varying mortgage payments to reflect a hotel's varying income stream. You probably won't find a loan with payments specifically pegged to your hotel's income, but you will find variable payment plans. One such 
loan is the adjustable-rate mortgage, but even these variable payment loans require a careful analysis to ensure a reasonable match with your hotel's income stream.

Figure 22.5

Hotel Cash Flow Issues

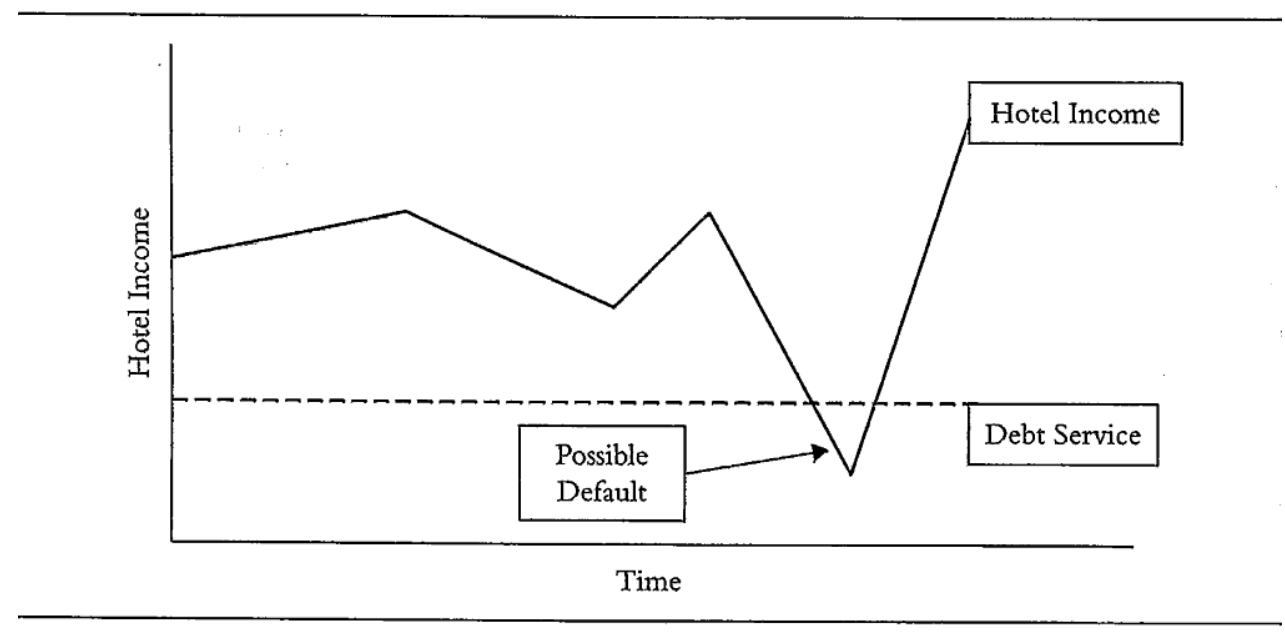

Broadly speaking, investors' mortgage choices can be viewed as a problem of matching assets to liability. Hotel revenues are the assets in this case, and debt payments are the liabilities. For investors concerned that their property income may not match their debt obligation as market conditions change, selecting a loan with a duration matching that of their hotel's income stream would be a reasonable approach to this problem. If the durations of both asset and liability are well matched with regard to changes in the discount rate, then both the hotel's income and debt service would move in the same direction by similar amounts. In that situation, you'd be reasonably assured of covering your debt service.

Although this strategy of matching asset and liability durations is used widely in managing interest rate risks for investment portfolios, to the best of our knowledge, the strategy hasn't been applied to hotel income and debt service.

So let's make that match. A common measure of the difference between the durations of two alternatives is the duration gap, defined as the difference in duration weighted by the relative size of the two alternatives. Thus, the duration gap is expressed as:

Duration Gap $=$ Duration of Assets $-($ Total Liabilities/Total Assets $) \times$ Durationof Liabilities

Consider the purchase of a $\$ 20$ million hotel financed by a 20 -year, fixed-rate mortgage with 0.8 loan-to-value ratio. Assume the duration of the hotel is five years and that of the loan is nine years. Based on these figures, the duration gap is: 
Duration Gap $=5-\frac{0.8 \times 20,000,000}{20,000,000} \times 9=-2.2$

Since the duration of the loan (liability) exceeds that of the hotel (asset), if you held this loan, you would be adversely affected if rates decline. Under this scenario, a decrease in rates will increase the value of the debt by a larger amount than the value of the hotel's income stream. That is, under this scenario, the value of the hotel decreases, while the market value of the debt obligation increases. You'd have to try to refinance this debt, and failing that you might end up with a loan default.

We just showed the situation with a decrease in interest rates and a duration gap in which the hotel's duration was shorter than that of the loan. The reverse case could also be a problem. That is, if the duration of the hotel were significantly longer than the duration of the debt, resulting in a positive duration gap, investors would correspondingly be exposed to an increase in interest rates. Because of its longer hotel duration, the hotel's value would fall by a disproportionately larger amount than the decline in the value of the debt, should rates rise. What you're looking for is a fully hedged position, one in which the duration gap is zero. Next, we discuss how managers and investors using conventional tools can hedge their position. For the example that we gave, the solution involves extending the duration of a hotel asset, reducing that of the debt, or some combination of both. We consider these alternatives and demonstrate how to use the duration gap expression to alleviate this problem.

\section{Duration Hedges}

- Extending a hotel's duration. One way to increase a hotel's duration is to include tenants who are willing to commit to long-term stays. This is one benefit of mixed-use developments that include residence units integrated into the hotel. Though such practices have often been justified on financial and market-demand grounds, this strategy can be interpreted as an implicit attempt to extend the duration of a hotel. Apartment leases will assure hotel operators of a steady stream of rent payments for the term of the tenant's contract, thereby offsetting some of the volatility of the hotel's income.

- Shorten the debt's duration. With adjustable-rate mortgages, the interest rate used to calculate the debt service is based on some benchmark interest rate that will vary over the life of the loan (usually the one-year T-bill rate or the LIBOR rate). This rate is combined with a fixed premium for the mortgage interest rate. As the benchmark rate 
changes each year, the mortgage payment changes for the following year. Thus, the borrower is assured of a constant fixed payment for the year. Because the benchmark rate is a component of the discount rate, as the benchmark rate changes, the corresponding payments will also change. The durations of such loans are short, perhaps on the order of one or two years. One way to reduce the duration of debt is to consider financing hotels using floating rate loans, which have an even shorter duration.

- Make use of swaps. In typical portfolios' interest rate immunization strategies, it is quite common to use interest rate swaps to alter the portfolio's duration. An interest rate swap is a third-party transaction in which a certain investment with a fixed payment at some interest rate is exchanged (swapped) for the same size investment, but with a variable payout determined by some short-term market rate such as LIBOR. This fixedfor-floating swap can be integrated with a portfolio comprising our hotel and the fixedrate mortgage to result in a matched-duration portfolio. For example, to shorten the duration of the fixed-rate mortgage, investors can simultaneously engage a counterparty in a swap transaction.

Say that a particular investor buys a hotel that pays out a stream of variable net operating incomes. Eighty percent of this purchase might be funded \ by a fixed-rate mortgage. Let's say that the interest rate for this financing is 6 percent. The hotel investor's cash flow is depicted in Figure 22.6.

This figure shows that the hotel investor has incurred interest rate risk-a duration mismatchsince the (fixed) repayment of mortgage debt service could exceed the (floating) hotel net operating income. To ameliorate this risk, the investor can enter into an interest rate swap with a counterparty, the goal being to eliminate the duration gap. As Figure 22.7 illustrates, the hotel receives a fixed-rate payment from a counterparty that matches the fixed-rate mortgage obligation while making a floatingrate payment based on the variable cash flow from the hotel net operating income.

The private agreement that facilitates the exchange of future cash flows between the hotel investor and the counterparty is called a swap (as depicted in Figure 22.8). This contract converts part of the hotel's fixed liability into floating liability with reduced duration.

So let's go back to our example, in which the $\$ 20$ million hotel purchase was financed by a 20 year, 80-percent fixed-rate mortgage with a duration gap of-2.2.

To offset this imbalance in duration, the hotel investor can swap a fixed rate for a floating rate on a portion of the liability portfolio. Say that the duration of the swap is 5; you can then calculate the 
amount of swap referenced, such that the duration gap equals zero.

$$
5=\frac{0.8 \times 20,000,000-\text { swap }}{20,000,000} \times 9+\frac{\text { swap }}{20,000,000} \times 5
$$

Figure 22.6

Hotel Cash Flow in a Fixed-Rate Mortgage

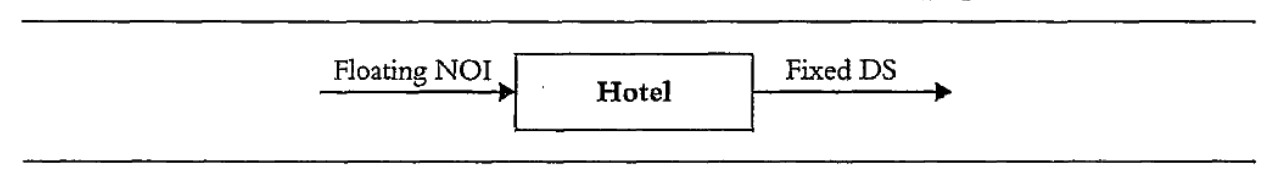

The preceding duration matching equation implies that the swap = \$11 million. The hedging strategy involves swapping $\$ 11$ million of the fixed-rate debt for floating debt. The resulting duration gap should be 0 .

Figure 22.7

Hotel Cash Flow in an Interest Rate Swap

Swap Floating Hotel Swap Fixed

Figure 22.8

Hotel Debt Swap

Counterparty

\section{Conclusion}

Since the absence of long-term tenant lease contracts imposes an additional risk for hotel owners, it is crucial to understand and manage this unique feature of hotel risk. We hope that this chapter gives you a framework to characterize this effect. Specifically, you have seen how a duration measure is adapted to quantify the sensitivity of hotel valuation to discount rate changes.

Whereas the "daily lease" feature is often viewed as a negative feature of hotels, as a hotel investor, you know that the ability to roll over leases with such frequency allows hotel operators to update the room rate structure to reflect dynamic economic conditions. The ability to align a hotel's revenue stream in the same direction as the discount rate gives hotel owners better control over their 
investments. Based on this argument, it is reasonable to assume that hotels will in general have a shorter duration than other commercial properties, such as office buildings and retail malls.

If you do have a duration mismatch, you now have strategies to address some of the financing issues that confront hotel investors, particularly the uncertainty arising from the lack of financial commitment from hotel tenants. Because a hotel's often volatile income stream is used to pay the monthly mortgage, this volatility can result in periods in which there is insufficient revenue to make the debt service payments. An adjustable-rate mortgage, therefore, might be a better financing choice than a fixed mortgage. Even with a fixed-rate mortgage, you can use an interest rate swap to help immunize your deal against interest rate risk. Such strategies-aligning a hotel's investment income with debt service-have not been studied closely in the context of hotel asset management but deserve further scrutiny.

\footnotetext{
${ }^{1}$ For formal treatment of duration, see B. Tuckman, Fixed Income Securities: Tools for Today's Markets, 2nd ed. (Hoboken, NJ: Wiley, 2002), 98; or R. W. Kopprasch, Understanding Duration and Volatility (New York: Salomon Brothers, 1985).
} 